\title{
Perspectives and attitudes of Jordanian medical and paramedical students toward surrogate pregnancy
}

This article was published in the following Dove Press journal: International Journal of Women's Health

\author{
Ayman G Mustafa ${ }^{1,2}$ \\ Karem H Alzoubi ${ }^{3}$ \\ Omar F Khabour ${ }^{4}$ \\ Mahmoud A Alfaqih² \\ 'College of Medicine, Qatar \\ University, Doha, Qatar; ${ }^{2}$ Faculty \\ of Medicine, Jordan University of \\ Science and Technology, Irbid 22I I0, \\ Jordan; ${ }^{3}$ Faculty of Pharmacy, Jordan \\ University of Science and Technology, \\ Irbid 221 I0, Jordan; ${ }^{4}$ Faculty of \\ Applied Medical Sciences, Jordan \\ University of Science and Technology, \\ Irbid 22110, Jordan
}

Purpose: This study aims at investigating the perspectives of Jordanian medical and paramedical students on surrogate pregnancy.

Methods: A questionnaire-based cross-sectional study design was used. The sample consisted of $n=328$ students of both genders. The questionnaire responses were numerically coded and analyzed across gender and the level of education.

Results: Approximately, 18\% of the students reported good awareness about the ethical dilemmas of surrogacy. The results showed a general reluctance to accept surrogate pregnancy as the majority ( $80.5 \%$ of male students and $97.6 \%$ of female students) had a negative attitude toward surrogacy. In addition, undergraduate students were less supportive to surrogate pregnancy than graduate students. Religious considerations were the main reason (accounts for about $70 \%$ ) for driving negative attitude toward surrogacy.

Conclusion: The findings of the study indicate a general reluctance toward accepting the concept of surrogate pregnancy, which is mainly due to religious reasons.

Keywords: perspectives, attitudes, medical, students, paramedical, surrogate pregnancy

\section{Introduction}

Infertility is a problem of global proportions, affecting about $8 \%-12 \%$ of couples worldwide. ${ }^{1}$ In fact, it was reported that infertile women suffer from mental disharmony, divorce, and ostracism. ${ }^{2}$ Driven by the need to find an alternative solution for infertile women when medical treatment fails, assisted reproductive technologies were proposed to help infertile women achieve pregnancy. Since their inception, the use of assisted reproductive technologies has been associated with ethical, legal, and social controversies. ${ }^{3}$ One of the highly debatable assisted reproductive technologies is surrogacy.

Surrogacy, or surrogate motherhood, is a method of assisted reproduction whereby a woman agrees to become pregnant for the purpose of gestating and giving birth to a child to be raised by others. ${ }^{4}$ It is both the oldest and the most controversial of all assisted reproductive technologies. ${ }^{5}$ While banned in many countries, surrogacy is legally practiced but inadequately regulated in some others, driving the need for a better level of regulation. ${ }^{6-9}$

Laws and regulations that ban or allow the practice of surrogate pregnancy consider several factors. For example, regulations governing this practice often differentiate between two types of surrogacy: 1) traditional surrogacy where the surrogate mother's own eggs are fertilized via intrauterine insemination by sperm of the future father ${ }^{10}$ 
and 2) gestational surrogacy where the surrogate mother carries the egg of the intended mother. In this case, in vitro fertilization (IVF) is used to make an embryo from the fertilization of the intended mothers' egg by the intended father's sperm..$^{10}$ Regulations also differentiate between commercial surrogacy where the surrogate mother is paid for pregnancy ${ }^{11}$ and altruistic surrogacy where the surrogate mother is simply reimbursed for the expenses of pregnancy. ${ }^{12}$

Herein, we list examples of the laws and regulations that govern surrogate pregnancy from several countries to better exemplify the wide range of the legal convolutions that surround this issue. In Germany, commercial, altruistic or any type of surrogacy arrangement is illegal. ${ }^{13}$ On one hand, only altruistic pregnancy is legal in Belgium. ${ }^{13}$ On the other hand, commercial and altruistic pregnancies are legal in Russia. ${ }^{14}$ In USA, the laws and regulations differ by state. California, for example, is considered a surrogate friendly jurisdiction and both types of surrogacy are legal. ${ }^{15}$ On the contrary, Michigan prohibits all types of surrogacy arrangements. ${ }^{9}$ Even in countries where surrogate pregnancy is a legal practice, limitations may exist in terms of the indications that permit surrogacy. For example, the American Society for Reproductive Medicine only permits gestational surrogacy as a tool for assisted pregnancy in the event that a medical condition poses a true risk of death to the intended mother if she carries a child. Furthermore, the culprit medical condition should be clearly labeled in the medical records of the intended mother. ${ }^{16}$ Noteworthy, success rates and other outcome parameters of gestational pregnancy are relatively high when compared with other means of assisted pregnancy and largely depend on the age of the egg donor. A recent statistics published by the Society for Assisted Reproductive Technology (SART) of USA demonstrated that for egg donors aged 35 years or below, the live birth success rate from gestational pregnancies was $50.5 \%$. This figure, however, dropped to as low as $9.2 \%$ in egg donors older than 42 years. ${ }^{17}$ Moreover, it appears that being brought up in a family, which involved surrogate pregnancy, does not negatively affect parent-child relationship or physiological development of children born from surrogate pregnancies. ${ }^{18}$

Attitude toward assisted reproductive technologies in general and surrogacy in particular seems to be variable worldwide and might be influenced by many factors such as religion, gender, age, socioeconomic status, and knowledge about the procedure. Attitude toward surrogacy has been studied across many countries yielding conflicting reports. For example, permissive attitude toward several new reproductive technologies such as IVF among women was reported in Sweden with the exception of surrogacy. ${ }^{19}$ In Germany, comparable rates of approval and disapproval toward surrogacy were reported, ${ }^{20}$ whereas less acceptance of surrogacy was noted in Turkey. ${ }^{21}$ However, in Japan, it is suggested that many factors including socioeconomic status affect a person's ability to clearly express an opinion about surrogacy.22 In contrast, Iranian infertile women believed that surrogacy is better than adoption or not having children, but generally, the attitude toward this method is not strongly positive. ${ }^{23,24}$

It is suggested that acceptance of surrogacy might be affected by gender. In Canada, for example, men were significantly more willing to consider using surrogacy. ${ }^{25}$ However, there was no significant difference between men and women in Germany. ${ }^{20}$ While in Japan, it was reported that there are gender differences in attitude toward this method and those differences are affected by information provided about the procedure. ${ }^{26}$

It is suggested that religion has an important impact on people's attitude toward surrogacy. Because surrogacy is forbidden in Islam, the majority of Islamic countries consider surrogacy as inadmissible from the point of view of the religious authorities though not prohibited by law. ${ }^{27-30}$ In a somehow similar manner, the Catholic Church is strongly against all forms of assisted reproduction, particularly those associated with third party assistance or surrogacy. ${ }^{31,32}$ In Egypt, Christians' beliefs concerning assisted reproduction were found to be identical to those of the Muslims..$^{33}$ However, surrogacy is not forbidden in the Jewish religion as the value of having a child in this community out weights any concern regarding assisted reproductive technologies. ${ }^{31,34}$ This attitude made Jews one of the leading communities in the research and development of new reproductive technologies. ${ }^{32}$

Jordan is an Arab speaking Middle-Eastern country. Islam is the major religion in Jordan, and it is estimated that $95 \%$ of the population are Muslims. ${ }^{35}$ In Jordan, the primary infertility rate was estimated to be $3.5 \%$ and the secondary infertility rate was estimated to be $13.5 \%{ }^{36}$ It is reported that Jordanian infertile women experience social, personal, and marital adversities. ${ }^{37}$ However, women receiving assisted reproduction technologies cope with the stress of being infertile. ${ }^{38}$ Attitude toward the use of third party-assisted reproduction in Jordan has not been reported. Thus, this study was designed to investigate the attitude of Jordanian medical and paramedical students toward surrogate pregnancy. The study also aims at exploring potential factors affecting attitude toward this procedure including gender and religious perspective. 


\section{Methods \\ Study setting}

This was a cross-sectional survey study. The study sample used was a convenient sample of medical and paramedical students at Jordan University of Science and Technology, Irbid, Jordan. The study was conducted during the period from November to December 2017. The protocol of the study was approved by the institutional review board (IRB) of Jordan University of Science and Technology. Only Jordanian students were included in the study.

\section{Sampling and sampling procedure}

Students were approached at open areas in the medical campus buildings and in class rooms during the rest period between classes. The questionnaire was distributed, in person, by the researchers and was self-completed by subjects in the presence of the researchers. Each participant was provided with a full explanation of the study and how to complete the questionnaire and was informed that participation in the study is voluntary. Then, each participant signed the consent form of the study. Participants were informed that the researcher would be available for any required assistance during scoring the questionnaire. Completed questionnaires were collected by the researchers and rechecked to insure full completion. Confidentiality was maintained as no names and addresses of participants were required. Data were aggregated into groups, and only the authors and the investigators were allowed to access the collected data. None of the participants opted to withdraw from the study.

\section{The study questionnaire}

The study questionnaire was aimed to investigate the perspectives of Jordanian medical and paramedical students on the ethics of surrogate pregnancy. The questionnaire consisted of eight questions selected based on literature review. The first four questions aimed to identify the participant gender, level of study, attitude, and reasoning for attitude toward surrogate pregnancy. The next four questions (yes or no questions) of the questionnaire aimed toward finding out whether the participant is well informed about surrogacyrelated controversial discussions, aware about the official position of his/her faith toward surrogacy, and willing to observe his/her faith regarding surrogacy and whether the participants will change his attitude to be more favorable to surrogacy if they know that surrogate pregnancy is the only mean to have kids. The study questionnaire was validated via reviewing by a panel of experts that included specialist physicians, a public health specialist, and a philosopher.
Then, the survey was piloted on 10 participants and was adjusted based on their feedback.

\section{Data analysis}

Data were analyzed using the IBM SPSS Version 21 statistical package. Age was represented as mean $\pm \mathrm{SD}$, while categorical variables were presented in terms of frequency and percentage (n, \%). Pearson's Chi-squared $\left(\chi^{2}\right)$ test was used to test for bivariate associations between demographic variables and perspective and attitude questionnaire items. Differences were considered statistically significant at $P<0.05$.

\section{Results}

A total of $n=328$ participants were recruited from medical and paramedical students, of whom 205 (62.5\%) students were males and 123 (37.5\%) students were females. According to the academic level, 239 (72.9\%) were undergraduate students and $89(27.1 \%)$ were graduate students. The mean age of participants was 21.5 years.

Attitudes of participants toward surrogacy per gender and per academic level are shown in Tables 1 and 2, respectively. The main source of the reported attitude was religion $(P<0.001, \mathrm{n}=328)$ as compared to educational and social factors.

Awareness about the ethical dilemmas associated with surrogate pregnancy and the opposing views and opinions about it in the community were also investigated. Less than one-fifth of the sample had such awareness, and it was neither correlated with gender $(P=0.46, \mathrm{n}=328)$ nor with the level of study $(P=0.68, \mathrm{n}=328)$. Knowledge about the official position of faith toward surrogacy was significantly more in females $(P<0.001, \mathrm{n}=328)$ and in graduate level of study ( $P=0.001, \mathrm{n}=328)$. Moreover, the willingness to adopt the official position faith toward surrogacy was significantly correlated with gender $(P=0.01, \mathrm{n}=328)$ but not with the level of study ( $P=0.93, \mathrm{n}=328)$. The final question inquired if the participant will become supportive to surrogacy in case it is the only hope for a couple to have children. Participants' responses to this question were significantly correlated with gender $(P<0.001, \mathrm{n}=328)$ but not with the level of study $(P=0.25, \mathrm{n}=328)$.

\section{Discussion}

Despite being the oldest method of assisted reproduction, until now surrogacy is considered the most controversial of all assisted reproductive technologies. ${ }^{5}$ Although surrogacy has become an integral part of infertility management in some 
Table I Comparing the attitude and perspectives toward surrogate pregnancy between Jordanian males and females

\begin{tabular}{|c|c|c|c|}
\hline & \multicolumn{2}{|l|}{ Gender } & \multirow[t]{2}{*}{$P$-value } \\
\hline & $\begin{array}{l}\text { Male } \\
\text { students (\%) }\end{array}$ & \begin{tabular}{|l} 
Female \\
students (\%)
\end{tabular} & \\
\hline \multicolumn{4}{|c|}{ I. Attitude toward surrogate pregnancy } \\
\hline Positive & 8.3 & 0.8 & \multirow[t]{3}{*}{$<0.001$} \\
\hline Neutral & 11.2 & 1.6 & \\
\hline Negative & 80.5 & 97.6 & \\
\hline \multicolumn{4}{|c|}{ 2. Source of attitude toward surrogacy } \\
\hline Education & 15.1 & 1.6 & \multirow[t]{3}{*}{$>0.01$} \\
\hline Religion & 69.8 & 69.1 & \\
\hline Social & 15.1 & 29.3 & \\
\hline \multicolumn{4}{|c|}{ 3. Awareness about the ethical dilemmas of surrogacy in the community } \\
\hline Yes & 17.1 & 20.3 & \multirow[t]{2}{*}{0.460} \\
\hline No & 82.9 & 79.7 & \\
\hline \multicolumn{4}{|c|}{ 4. Knowing the official position of your faith toward surrogate pregnancy } \\
\hline Yes & 42 & 80.5 & \multirow[t]{2}{*}{$>0.001$} \\
\hline No & 58 & 19.5 & \\
\hline \multicolumn{4}{|c|}{$\begin{array}{l}\text { 5. Willingness to observe the official position of your faith toward } \\
\text { surrogate pregnancy }\end{array}$} \\
\hline Yes & 82 & 91.9 & \multirow[t]{2}{*}{0.01} \\
\hline No & 18 & 8.1 & \\
\hline \multicolumn{4}{|c|}{$\begin{array}{l}\text { 6. Become supportive to surrogacy if it is the only mean to have kids } \\
\text { for a couple }\end{array}$} \\
\hline Yes & 21.5 & 2.4 & \multirow[t]{2}{*}{$>0.001$} \\
\hline No & 78.5 & 97.8 & \\
\hline
\end{tabular}

countries, it is still forbidden and rejected in many nations. The ethical, legal, and religious dilemmas associated with surrogacy resulted in highly diverse attitudes toward it. .,5,9,31 $^{-1}$ While some people appreciate the merits of surrogate pregnancy and its role in creating a window of hope for infertile women to have children, many others find it morally problematic and an unjustified technology.

It was suggested that people's attitude toward surrogacy might be influenced by multiple factors, including gender, culture, and religious perspectives. In the Arab world, where the Jordanians belong, it is thought that religious rules strictly control assisted reproduction and those rules do not allow involvement of a third party in the procedure. ${ }^{33}$ This seems in harmony with current findings as most of the participants in the current study ( $86.9 \%$ of participants) were against surrogacy, whereas only $5.5 \%$ of them were supportive to this method and $7.6 \%$ of the sample was neutral toward it.

Current results showed that the attitude of $69.5 \%$ of the participants was related to religion, demonstrating that religious views appear to have an important impact on the
Table 2 Comparing the attitude and perspectives toward surrogate pregnancy between Jordanian undergraduate and graduate students

\begin{tabular}{|c|c|c|c|}
\hline & \multicolumn{2}{|l|}{ Level of study } & \multirow[t]{2}{*}{$P$-value } \\
\hline & $\begin{array}{l}\text { Undergraduate } \\
\text { students (\%) }\end{array}$ & $\begin{array}{l}\text { Graduate } \\
\text { students (\%) }\end{array}$ & \\
\hline \multicolumn{4}{|c|}{ I. Attitude toward surrogate pregnancy } \\
\hline Positive & 9 & 4.2 & \multirow[t]{3}{*}{0.063} \\
\hline Neutral & 11.2 & 6.3 & \\
\hline Negative & 79.8 & 89.5 & \\
\hline \multicolumn{4}{|c|}{ 2. Source of attitude toward surrogacy } \\
\hline Education & 13.5 & 8.8 & \multirow[t]{3}{*}{0.103} \\
\hline Religion & 60.7 & 72.8 & \\
\hline Social & 25.8 & 18.4 & \\
\hline \multicolumn{4}{|c|}{ 3. Awareness about the ethical dilemmas of surrogacy in the community } \\
\hline Yes & 16.9 & 18.8 & \multirow[t]{2}{*}{0.68} \\
\hline No & 83.1 & 81.2 & \\
\hline \multicolumn{4}{|c|}{ 4. Knowing the official position of your faith toward surrogate pregnancy } \\
\hline Yes & 70.8 & 51 & \multirow[t]{2}{*}{0.001} \\
\hline No & 29.2 & 49 & \\
\hline \multicolumn{4}{|c|}{$\begin{array}{l}\text { 5. Willingness to observe the official position of your faith toward } \\
\text { surrogate pregnancy }\end{array}$} \\
\hline Yes & 85.4 & 85.8 & \multirow[t]{2}{*}{0.93} \\
\hline No & 14.6 & 14.2 & \\
\hline \multicolumn{4}{|c|}{$\begin{array}{l}\text { 6. Become supportive to surrogacy if it is the only mean to have kids } \\
\text { for a couple }\end{array}$} \\
\hline Yes & 18 & 13 & \multirow[t]{2}{*}{0.25} \\
\hline No & 82 & 87 & \\
\hline
\end{tabular}

students' perspective toward surrogacy. Indeed, a similar trend was reported by previous studies showing that religion is a robust determinant of attitudes toward surrogacy. ${ }^{33}$ In the current study, religion had a stronger effect on the students' perspective about surrogacy compared to social values and education. Given the fact that Islam is the predominant religion in Jordan and that surrogacy is forbidden in Islam, ${ }^{39,40}$ one might expect that students who made their opinion based on religious views are probably against surrogacy. Interestingly, beliefs of the Arab orthodox Christians concerning assisted reproductive technologies and surrogacy in particular were reported to be similar to that of Muslims. ${ }^{33}$ This fact emphasizes that religion is the main factor, which shaped students' attitude toward surrogacy. Although $85.7 \%$ of the students reported that they are willing to follow the official position of their faith toward surrogate pregnancy, only $56.4 \%$ of the students were aware of it. This might be explained by the fact that surrogacy is very uncommon assisted reproductive technology method in Jordan compared to other technologies such as IVF. Thus, Jordanians might 
be more aware of the official position of their faith toward the more commonly used assisted reproductive technology methods in Jordan.

In addition to the fact that religion was the main factor affecting the students' attitude toward surrogacy, probably in those who are against it, the results showed that those students would not change their mind if they knew that surrogate pregnancy is the only mean to have children for a couple. This indicates that students who are against surrogacy made their opinion based on a firm foundation and sympathy toward infertile couples would not change their attitude toward this procedure. Such firm foundation is typical with religious opinions in general.

It is thought that gender might have an effect on peoples' perspective on surrogacy..$^{20,25,26}$ In the current study, more female students were against surrogate pregnancy. However, comparable rates in both genders were found to support it. In fact, more male students appear to have a neutral attitude, suggesting that those students might have a difficulty in expressing a clear opinion toward this method. The results also showed that both males and females were almost equally influenced by their religious background. Furthermore, more males made their opinion based on education while females' opinions were more based on social values. In addition to that, females appear to be more aware of the official position of their faith toward surrogate pregnancy and more willing to follow it. However, males were more willing to accept the use of surrogate pregnancy if it is the only means to have children for a couple. In contrast, no significant difference was found regarding the awareness about none religious discussions and views about surrogacy between genders; again this affirms the role of religion in the students' attitude toward this procedure.

In this study, the potential effect of the academic level of study on the attitude toward surrogacy was evaluated by comparing the answers of graduate and undergraduate students. The only significant difference between graduate and undergraduate students was in the awareness of the official position of their faith toward surrogacy where graduate students appear to have a better knowledge about the religious perspective toward the procedure.

\section{Limitations}

Among the limitations of the current study is that only medical and paramedical students were included. A larger study involving students from other disciplines and from the general population is strongly recommended. In addition, more in depth approaches such as focus groups and interviews might be more appropriate for such kind of studies.

\section{Conclusion}

The study reported the attitude of Jordanian medical students toward surrogacy. The findings of the study indicate a general reluctance toward accepting the concept of surrogate pregnancy, which is mainly due to religious reasons. Results of this study also suggest lesser impact of education on the acceptance or refusal of surrogacy compared to other factors. More studies involving Jordanian fertile and infertile women are needed to accurately evaluate the general attitude toward surrogacy in the Jordanian society.

\section{Acknowledgment}

The study was supported by grant \# 5R25TW010026-02 from the Fogarty International Center of the US National Institutes of Health.

\section{Author contributions}

AGM, KHA, OFK, and MAA designed the study tool and procedure. AGM and OFK carried out data collection. AGM and KHA analyzed the results of the study. AGM, KHA, OFK, and MAA interpreted the study results. AGM, KHA, OFK, and MAA drafted the manuscript. All authors contributed toward data analysis, drafting and critically revising the paper and agree to be accountable for all aspects of the work.

\section{Disclosure}

The authors report no conflicts of interest in this work.

\section{References}

1. Inhorn MC. Global infertility and the globalization of new reproductive technologies: illustrations from Egypt. Soc Sci Med. 2003; 56(9):1837-1851.

2. Sciarra J. Infertility: an international health problem. Int J Gynaecol Obstet. 1994;46(2):155-163.

3. Londra L, Wallach E, Zhao Y. Assisted reproduction: Ethical and legal issues. Semin Fetal Neonatal Med. 2014;19(5):264-271.

4. Aramesh K. Iran's experience with surrogate motherhood: an Islamic view and ethical concerns. J Med Ethics. 2009;35(5):320-322.

5. Ciccarelli JC, Beckman LJ. Navigating rough waters: an overview of psychological aspects of surrogacy. J Soc Issues. 2005;61(1):21-43.

6. Brahams D. The hasty British ban on commercial surrogacy. Hastings Cent Rep. 1987;17(1):16-19.

7. Charo RA. Legislative approaches to surrogate motherhood. The Journal of Law, Medicine \& Ethics. 1988;16(1-2):96-112.

8. Dar S, Lazer T, Swanson S, et al. Assisted reproduction involving gestational surrogacy: an analysis of the medical, psychosocial and legal issues: experience from a large surrogacy program. Hum Reprod. 2015;30(2):345-352.

9. Drabiak K, Wegner C, Fredland V, Helft PR. Ethics, law, and commercial surrogacy: a call for uniformity. J Law Med Ethics. 2007;35(2):300-309.

10. English ME, Mechanick-Braverman A, Corson SL. Semantics and science: the distinction between gestational carrier and traditional surrogacy options. Womens Health Issues. 1991;1(3):155-157.

11. Parks JA. Care ethics and the global practice of commercial surrogacy. Bioethics. 2010;24(7):333-340. 
12. Baker BM. A case for permitting altruistic surrogacy. Hypatia. 1996; 11(2):34-48.

13. Brunet L, Carruthers J, Davaki K, King D, Marzo C, McCandless J. A Comparative Study on the Regime of Surrogacy in EU Member States. Brussels: European Parliament; 2013. Available from: http:// www.europarl.europa.eu/RegData/etudes/etudes/join/2013/474403/ IPOL-JURI_ET(2013)474403_EN.pdf. Accessed July 29, 2015.

14. Svitnev K. Legal regulation of assisted reproduction treatment in Russia. Reprod Biomed Online. 2010;20(7):892-894.

15. Lawrence DE. Surrogacy in California: Genetic and Gestational Rights. Golden Gate UL Rev. 1991;21:525.

16. Practice Committee of the American Society for Reproductive Medicine and Practice Committee of the Society for Assisted Reproductive Technology. Recommendations for practices utilizing gestational carriers: a committee opinion. Fertil Steril. 2015;103(1):e1-e8.

17. Toner JP, Coddington CC, Doody K, et al. Society for Assisted Reproductive Technology and assisted reproductive technology in the United States: a 2016 update. Fertil Steril. 2016;106(3):541-546.

18. Golombok S, Maccallum F, Murray C, Lycett E, Jadva V. Surrogacy families: parental functioning, parent-child relationships and children's psychological development at age 2. J Child Psychol Psychiatry. 2006;47(2):213-222.

19. Wennberg AL, Rodriguez-Wallberg KA, Milsom I, Brännström M. Attitudes towards new assisted reproductive technologies in Sweden: a survey in women 30-39 years of age. Acta Obstet Gynecol Scand. 2016; 95(1):38-44.

20. Stöbel-Richter Y, Goldschmidt S, Brähler E, Weidner K, Beutel M. Egg donation, surrogate mothering, and cloning: attitudes of men and women in Germany based on a representative survey. Fertil Steril. 2009;92(1):124-130.

21. Baykal B, Korkmaz C, Ceyhan ST, Goktolga U, Baser I. Opinions of infertile Turkish women on gamete donation and gestational surrogacy. Fertil Steril. 2008;89(4):817-822.

22. Suzuki K, Hoshi K, Minai J, Yanaihara T, Takeda Y, Yamagata Z. Analysis of national representative opinion surveys concerning gestational surrogacy in Japan. Eur J Obstet Gynecol Reprod Biol. 2006;126(1): 39-47.

23. Kian EM, Riazi H, Bashirian S. Attitudes of Iranian infertile couples toward surrogacy. J Hum Reprod Sci. 2014;7(1):47-51.

24. Rahmani A, Sattarzadeh N, Gholizadeh L, Sheikhalipour Z, Allahbakhshian A, Hassankhani H. Gestational surrogacy: Viewpoint of Iranian infertile women. J Hum Reprod Sci. 2011;4(3):138-142.
25. Daniluk JC, Koert E. Childless Canadian men's and women's childbearing intentions, attitudes towards and willingness to use assisted human reproduction. Hum Reprod. 2012;27(8):2405-2412.

26. Minai J, Suzuki K, Takeda Y, Hoshi K, Yamagata Z. There are gender differences in attitudes toward surrogacy when information on this technique is provided. Eur J Obstet Gynecol Reprod Biol. 2007;132(2): 193-199.

27. Ahmad NH. Assisted reproduction - Islamic views on the science of procreation. Eubios J Asian Int Bioeth. 2003;13(2):59-61.

28. Atighetchi D. Islamic tradition and medically assisted reproduction. Mol Cell Endocrinol. 2000;169(1-2):137-141.

29. Chamsi-Pasha H, Albar MA. Assisted reproductive technology: Islamic Sunni perspective. Hum Fertil. 2015;18(2):107-112.

30. Fadel HE. The Islamic viewpoint on new assisted reproductive technologies. Fordham Urban Law J. 2002;30(1):147-157.

31. Brinsden PR. Gestational surrogacy. Hum Reprod Update. 2003;9(5): 483-491.

32. Schenker JG. Assisted reproductive practice: religious perspectives. Reprod Biomed Online. 2005;10(3):310-319.

33. Aboulghar M, Serour GI, Mansour RT. Ethical aspects and regulation of assisted reproduction in the Arabic-speaking world. Reprod Biomed Online. 2007;14:143-146.

34. Schenker JG. Assisted reproductive technology: perspectives in Halakha (Jewish religious law). Reprod Biomed Online. 2008;17 Suppl 3: $17-24$.

35. Pew Research Center [webpage on the Internet]. The world's Muslims: unity and diversity; 2012. Available from: http://www.pewforum. org/2012/08/09/the-worlds-musl. Accessed August 9, 2012.

36. Rutstein SO, Shah IH. Infecundity, Infertility, and Childlessness in Developing Countries. DHS Comparative Reports No. 9. Calverton, MD, USA: ORC Macro and the World Health Organization; 2004.

37. Obeisat S, Gharaibeh MK, Oweis A, Gharaibeh H. Adversities of being infertile: the experience of Jordanian women. Fertil Steril. 2012; 98(2):444-449.

38. Obeidat HM, Hamlan AM, Callister LC. Missing Motherhood: Jordanian Women's Experiences with Infertility. Adv Psychiatry. 2014;2014(3):1-7.

39. Alaro AA. Assisted Reproductive Technology (ART): The Islamic Law Perspective. Islam and Bioethics. 2012:95-108.

40. Shabana A. Foundations of the Consensus against Surrogacy Arrangements in Islamic Law. Islamic Law and Society. 2015;22(1-2):82-113.
International Journal of Women's Health

\section{Publish your work in this journal}

The International Journal of Women's Health is an international, peerreviewed open-access journal publishing original research, reports, editorials, reviews and commentaries on all aspects of women's healthcare including gynecology, obstetrics, and breast cancer. The manuscript management system is completely online and includes

\section{Dovepress}

a very quick and fair peer-review system, which is all easy to use. Visit http://www.dovepress.com/testimonials.php to read real quotes from published authors. 